\title{
Borsa İstanbul'a Kayıtlı Firmaların Halka Arz Öncesi Ve Sonrası Finansal Karakteristikleri
}

\author{
İbrahim Emre KARAA*
}

\section{ÖZET}

Çalışmada, halka arz öncesi ve sonrası süreçlerinde 37 firmanın mali tablolarından elde edilen 18 finansal oran analiz edilerek benzeşen ve ayrişan finansal karakteristikler belirlenmeye çalışılmıştır. Halka arz öncesine göre finansal oranlarda farklılıklar t-testi ile belirlenmiş, farklılığın en önemli ayrımcılarının aktif devir hızı, maddi duran varlık devir hızı, net işletme sermayesi devir hızl, dönen varlıklar/toplam aktifler ve duran varlıklar/toplam aktifler olduğu logaritmik regresyon yöntemi ile gösterilmiştir. Halka arz olasılıkları bu oranlar üzerinden hesaplanmış, halka arz öncesi ve sonrası yoğunlaşmalar belirlenmiştir. Farklı sektör ve yillara rağmen yoğunlaşmalar, önemli ölçüde homojen finansal davranışlar olduğunu göstermektedir. Bulgular, halka arz güdülerinden (incentives) büyüme, bilinirliğin artması önermelerini destekler niteliktedir. Kârların halka arzdan sonra düşüşü, makyajlama ihtimalini düşündürmektedir.

Anahtar Kelimeler: Halka arz öncesi, halka arz sonrası, makyajlama, yoğunluk analizi. JEL Sinıflandirması: G30, G39.

\section{Financial Characteristics of Pre and Post IPO Firms Traded in Borsa Istanbul}

\section{ABSTRACT}

In the study, 18 financial ratios of 37 listed firms are analyzed pre and post IPO process to determine similar or differentiated financial characteristics. The differences in financial ratios analyzed by t-test and assets turnover, tangible assets turnover, net working capital turnover, current assets over total assets, and long-term assets over total assets ratios are the most discriminative ratios as logistic regression suggested. The probability of IPOs are calculated with the same ratios. Moreover, densities are estimated for pre and post IPO periods and even the time intervals and industries are different, firms highly cluster and homogeneous financial behaviours in pre and post IPO periods. Findings support the growth and publicity incentives of going public. The lowered profits after IPO address window dressing possibilities.

Keywords: Pre-IPO, post-IPO, window dressing, density analysis.

Jel Classification: G30, G39

\footnotetext{
*Yrd.Doç.Dr.İbrahim Emre Karaa, Celal Bayar Üniversitesi, Uygulamalı Bilimler Yüksekokulu, emre.karaa@cbu.edu.tr
} 


\section{GİRIŞ}

Halka arz, firmaların borsalar veya örgütlenmiş diğer piyasalar aracılığıyla yüksek tutarlarda fon bulmasının en doğrudan yoludur. Firmaların halka arz kararları stratejiktir çünkü firmanın iç ve dış çevresini etkilemesinin yanı sıra, geleceğini de bağlayacak olan firma tarihinin en önemli olaylarından biridir. Firmanın iç çevresindeki yöneticiler, çalışanlar, yönetim kurulu bu kararla birlikte halkın önüne çıkacağının, yepyeni bir çevrede değerlendirileceğinin farkındadır. Firmanın dış çevresinde ise yeni hukuki statü, vergiler, finansal çevre ile karşılaşılacaktır.

Firmalar birbirinden çok farklı gerekçelerle halka arza gidebilirler. Literatürde halka arza ilişkin olarak hisse senetlerinin uzun dönem performansı, düşük-yüksek fiyatlama konuları çokça çalışılmış olmasına rağmen, firmaların halka arz güdülerini (sâik/incentives) açıklamaya çalışan az sayıda teorik ve ampirik çalışma bulunmaktadır. Brau (2010: 407) halka arz güdülerini, büyüme isteği ve firsatları (örn. Schiozer, vd., 2010), piyasada hisse fiyatlarının o periyotta pahalı oluşu (market timing) (örn. Schultz, 2003; Altı, 2005), optimal sermaye yapısı için A ğırlıklı Ortalama Sermaye Maliyetini (WACC) düşürmek (örn. Kraus ve Litzenberger, 1973), bankalar karşısında pazarlık gücünü arttırmak (örn. Basile, 1988; Pagano et al., 1998; Rajan ve Servaes, 1997), devredilen karlar ve borç kapasitesinin dolması, yetememesi (Sinyal verme) (örn. Brealey vd., 1977), girişimcinin nakde dönmesi (Cash-out) ya da cash-out için bir adım atıp şirketi piyasaya çıkarmak (örn. Brau, vd., 2010; Pagano vd., 1996; 1998; Kim ve Weisbach, 2005), sahipliği çeşitlendirerek riskleri paylaşmak (örn. Chemmahur ve Fulghieri, 1999), tanınırlığın bilinirliğin artması (örn. Demers ve Levennen, 2003), analistlerin izlemeleri ile izlemenin güçlenmesi, sürü psikolojisi (herding) olarak belirlemektedir. Elbette, halka arz olgusunun bir tek faktörle açıklanması mümkün değildir. Piyasa şartları kadar, firmanın içinde faaliyet gösterdiği genel ekonomik ve sektöre ilişkin şartların da bu kararlarda etkisi bulunmaktadır.

Halka arz sonrasında firmaların sermaye yapılarında meydana gelen değişime bağlı olarak finansal politikalarda da bir değişim olması beklenir. Firmaların finansal oranları üzerinden izlenebilen örneğin sermaye yapısı politikaları, borçluluk oranları ile incelenmektedir. Welch (2004: 106), halka arzdan önceki borçlanma oranlarının, halka arzı müteakiben halka arz öncesindeki seviyelerine doğru hareket ettiğini bulgulamış, hisse fiyatlarıyla borçlanma oranlarının ilişkisini araştırmıştır. Firmaların borçlanma politikalarının halka arzdan sonra değişmediği, devamlılık gösterdiği belirlenmiştir (Lemmon,vd., 2008: 1605). Bu bulgular, halka arz ile toplam varlıklar içinde borçlanmaların ağırlığını nispeten azalttıklarını ancak hemen sonrasında halka arz öncesindeki borçlanma davranışlarını devam ettirdiklerini göstermektedir. $\mathrm{Bu}$ durum, halka arzın gerekçesinin borçların azaltılması olmadığını, belki firmaların bankalar karşısında pazarlık güçlerini artırmış olabileceklerini düşündürmektedir. Firmaların halka arz öncesi ile sonrası finansal karakteristiklerinin veri madenciliği yöntemleriyle izlenmesi sayesinde halka arz gerekçesi olarak ileri sürülen bazı argümanların geçerliliği ile ilgili ipuçları verecektir.

Halka arz öncesi ve sonrası incelemeleri ile firmaların önceden halka arz sürecini yürütürken uyguladıkları politikalar da görülebilecektir. Halka arz süreci, uzun bir dönem gerektirir ve bu süre içinde hazırlıklar yapılır. Hazırlık safhasında, mali tabloların bağımsız denetime açılacağı fikrinden hareketle, hesapların ve raporların uygunlaştırılma ve uyumlaştırma faaliyetleri yürütülmektedir. Ancak bu süreç kâr yönetimi (Earnings 
management) şüphesini de ortaya çıkartır çünkü girişimin sahipleri yüksek kârlılığı olan bir firma hissesini iyi fiyata satabileceklerdir. Kâr yönetimi uygulamaları, finansal tablolarını makyajlamalarını, teknik tabiriyle vitrin süsleme (window dressing) olgusunu içerir. Yatırımcıların erişim sağladıkları ve en önemli bilgi dayanakları izahnameler ve bu izahnamelerde yer alan üç yıllık mali tablolardır dolayısıyla mali tablo bilgilerinin ve bunlardan elde edilen finansal oranların hisse fiyatlamasında etkisi olması beklenir.

Öncesi ve sonrası çalışmaları, sebep-sonuç ilişkisini açıklayan çalışmalar olmamakla birlikte, bir vakanın değerlendirilmesi ile ilgili olarak literatürde vaka analizleri olarak yerini almaktadır. Vaka analizleri genellikle spesifik bir olayın hisse fiyatlarına olan etkisini ölçmek, riskliliklerini belirlemeye yöneliktir. Örneğin, Mikkelson, vd. (1997: 281), halka arz sonrasında firmaların varlıklarda anlamlı bir büyüme olduğunu belirlemişlerdir.

Bu çalışmada, Türkiye'de Borsa İstanbul'a kayıtlı firmaların halka arz öncesi ve sonrası finansal karakteristikleri ilk defa araştırılmıştır. Diğer çalışmalardan farklı olarak sadece belli bir konu, örneğin borçlanma davranışı ile sınırlı kalınmayıp, borçlanma faaliyet, likidite ve kârlılık oranlarından elverişli 18 finansal oran analiz edilmektedir. Firmaların finansal yönetim politikaları hakkında fikir veren, finansal oranlar kullanılarak firmaların halka arz öncesi ve sonrasındaki davranış paternleri belirlenmiştir. Bu aynı zamanda, diğer tüm faktörler pozitif olduğunda bir firmanın halka arz olasılığının değerlendirilebileceği anlamına da gelmektedir.

\section{VERILER VE ÖRNEKLEM SEÇIMI}

Çalışmamızda kullanılan finansal oranlar, firmaların kârlılıkları, likidite durumu, finansal yapısı, nasıl yönetildiğini gösterir devir hızlarından elde edilen oranlardır. Halka arzı gerçekleşmiş, halka arzdan 3 yıl öncesi ve sonrası mali verilerine ulaşılabilen, mali sektör dışında faaliyet gösteren 37 firmanın 18 finansal oranı analiz için uygun bulunmuştur. Halka arz edilen firma ve araştırılan finansal oranlar gerçekte çok daha fazla olmasına rağmen, verilerin tutarlı olmayışı, eksik oluşu sebebiyle anlamlı sonuç verebilecek 37 firma verisi ve 18 oran tespit edilmiştir. Firma hisse kodları şunlardır: "AKENR, AKSUE, ALKIM, ALYAG, ARENA, ARMDA, AYEN, BJKAS, BRKO, BSOKE, BURVA, DOBUR, ERSU, ESCOM, FENER, FVORI, GEREL, GSDHO, IPEKE, ISFIN, ITTFH, KARSN, KOZAA, LINK, METUR, MNDRS, NUHCM, RANLO, SANKO, SKPLC, SODA, TAVHL, TCELL, TEKTU, TTKOM, ZOREN”

Merkez bankası sektör bilanço verileri, merkez bankasının internet sayfasından elde edilmiştir, firma verilerine ise Finnet Mali Analiz yazılımı ile ulaşılmıştır.

Vaka analizlerinde kullanılan anormal getirilerin hesaplanması prosedürü (bkz. Apergis ve Apergis, 2016) uygulanarak, beklenmeyen oranlar (unexpected ratios) hesaplanmıştır (örn. Lemmon,vd, 2008). Buna göre beklenmeyen oranlar;

$$
\begin{aligned}
& U R=r_{\text {firma }}-R_{T R} \\
& U r=\text { Beklenmeyen Oran } \\
& r_{\text {firma }}=\text { Kote Firmalarin finansal oranlarl } \\
& R_{T R}=\text { MB tüm firmalarin finansal oranlart }
\end{aligned}
$$


ile hesaplanmıştır. Tablo 1'de tanımlayıcı istatistikler, hızlı bir karşılaştırmayı göstermesi bakımından t-testi sonuçları ile birlikte verilmiştir. Halka arz öncesine göre sonrasına ait farklılıklar ve benzerlikler gösteren oranlar belirlenmiştir.

Tablo 1. Tanımlayıcı istatistikler ve t-testi sonuçları

\begin{tabular}{|c|c|c|c|c|c|c|c|}
\hline & Önce & $(n=111)$ & Sonre & $(n=111)$ & Grup O & talama 1 & arkları \\
\hline Beklenmeyen Oranlar & Ort & Std. Sap. & Ort & Std. Sap. & $\begin{array}{l}\text { Diff } \\
\text { (ort) }\end{array}$ & $\mathrm{Ha} / \mathrm{Ho}$ & $\operatorname{Pr}$ \\
\hline Aktif Devir Hızı & -0.58 & 1.31 & -0.34 & 1.16 & -0.24 & diff $>0$ & 0.9237 \\
\hline Alacak Devir Hızı & 4.07 & 30.77 & 7.96 & 33.82 & -3.88 & diff $>0$ & 0.8139 \\
\hline Cari Oran & -14.90 & 43.90 & -32.2 & 59.03 & 17.30 & $\operatorname{diff}<0$ & 0.9930 \\
\hline Duran Varlık Devir Hızı & 10.17 & 33.38 & 9.82 & 46.78 & 0.35 & $\operatorname{diff}=0$ & 0.9487 \\
\hline $\begin{array}{l}\text { Duran Varlıklar/Aktif } \\
\text { Toplamı (\%) }\end{array}$ & 17.83 & 29.52 & 21.5 & 24.95 & -3.69 & diff $>0$ & 0.8419 \\
\hline $\begin{array}{l}\text { Net işletme sermayesi devir } \\
\text { hyzı }\end{array}$ & -6.22 & 48.26 & -17.2 & 34.44 & 10.95 & $\operatorname{diff}<0$ & 0.9734 \\
\hline $\begin{array}{l}\text { Dönen Varlıklar/Aktif } \\
\text { Toplamı (\%) }\end{array}$ & -3.29 & 29.53 & -3.77 & 25.19 & 0.48 & diff $=0$ & 0.8975 \\
\hline Kaldıraç Oranı (\%) & -45.17 & 21.72 & -39.8 & 21.79 & -5.34 & $\operatorname{diff}>0$ & 0.9656 \\
\hline $\begin{array}{l}\text { Kısa Vadeli Fin. Borç/Toplam } \\
\text { Borç (\%) }\end{array}$ & 1.05 & 29.53 & 3.04 & 3.90 & -1.99 & diff $>0$ & 0.6995 \\
\hline $\begin{array}{l}\text { Kısa Vadeli Borç/Toplam Borç } \\
\text { (\%) }\end{array}$ & -82.06 & -76.56 & -86.5 & 18.22 & 4.44 & $\operatorname{diff}<0$ & 0.9635 \\
\hline Likidite Oranı & 160.04 & 746.48 & 30.9 & 112.17 & 129.18 & $\operatorname{diff}<0$ & 0.9630 \\
\hline $\begin{array}{l}\text { Maddi Duran Varlık Devir } \\
\text { Hızı }\end{array}$ & -22.98 & 4.24 & -20.5 & 7.44 & -2.48 & diff $>0$ & 0.9987 \\
\hline Nakit Oran & 14.73 & 22.96 & 6.31 & 22.69 & -12.39 & diff $>0$ & 0.7184 \\
\hline Net Dönem Karı / Özsermaye & 6.43 & 13.01 & 4.57 & 11.71 & 1.87 & diff $<0$ & 0.8686 \\
\hline $\begin{array}{l}\text { Net Dönem Karı/Toplam } \\
\text { Aktifler }\end{array}$ & -7.43 & 41.27 & -30.5 & 62.62 & -7.86 & diff $=0$ & 0.7446 \\
\hline $\begin{array}{l}\text { Vergi Öncesi } \\
\text { (Kar/Zarar)/Özkaynak }\end{array}$ & -4.40 & 27.54 & -5.09 & 11.31 & 0.68 & $\operatorname{diff}=0$ & 0.8091 \\
\hline Özsermaye Devir Hızı & 10.23 & 47.18 & -3.01 & 29.08 & 13.24 & $\operatorname{diff}<0$ & 0.9936 \\
\hline İşletme Sermayesi Devir Hızı & -3.25 & 0.81 & -2.71 & 2.38 & -0.54 & diff $>0$ & 0.9874 \\
\hline
\end{tabular}

Duran varlık devir hızı, dönen varlıklar/toplam aktifler, net dönem kârı/toplam aktifler ve vergi öncesi kâr/özkaynak oranlarının, halka arzdan sonra değişmemiş olma olasılıkları sırasıyla (\%94.87, \%89.75, \%86.86, \%80.91) olarak belirlenmiştir. \%90 olasılığın altında kalan oranlar ise, Alacak devir hızı, duran varlıklar/toplam aktifler ve dönen varlıklar/toplam aktifler, kısa vadeli finansal borçlar, nakit oran, özsermaye ve net dönem karı/toplam aktifler, vergi öncesi kârlar/özkaynaklar olduğu görülmektedir.

Finansal oranların halka arzdan öncesi ve sonrası Kernel yoğunlukları grafikleri ile gösterilmektedir. Kernel yoğunlukları, firmaların beklenen ve beklenmeyen finansal oranlarının hangi aralıklarda yoğunlaştığının görülmesine imkân vermektedir. Kesikli çizgiler halka arz öncesini, düz çizgiler ise sonrasını göstermektedir. 
Şekil 1. Aktif devir hızı/Alacak devir hızı/Cari oran Kernel yoğunlukları
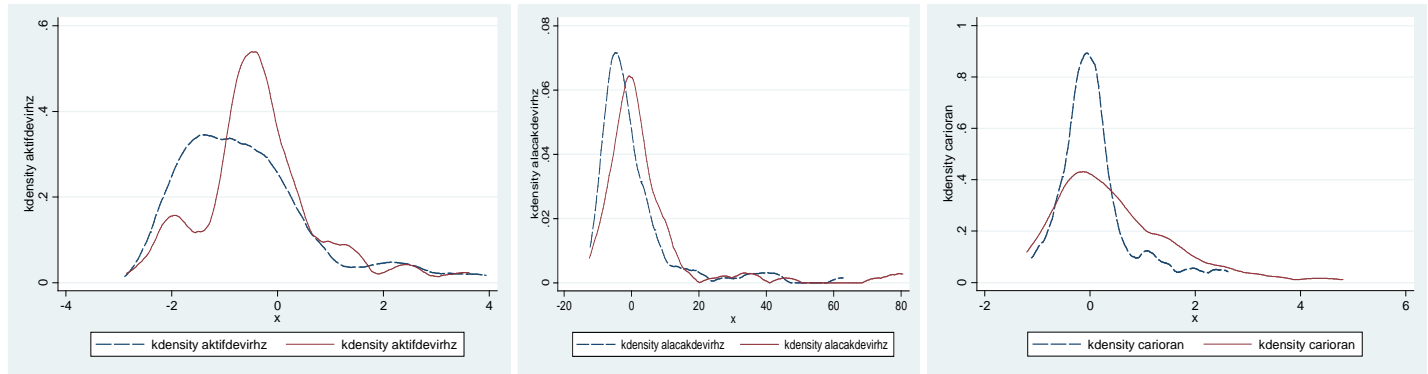

Şekil 1'den de izlenebileceği gibi sırasıyla, aktif devir hızlarının, halka arz öncesinde $(-2,1)$ aralığında, halka arz sonrasında ise yoğunlaşmanın $(-0.5,0.5)$ aralığında olduğu, sonrasında daha yüksek oranların görülebildiği; alacak devir hızlarının halka arz öncesi ve sonrası oldukça benzer biçimde $(-10,10)$ aralığında olduğu, cari oranların halka arz öncesi ve sonrasında $(-0.1,1)$ yoğunlaştı̆̆ı ancak halka arzdan önce oldukça yüksek seyrettiği görülmektedir.

Şekil 2. Dönen V. Aktif toplamı/Duran V.devir hızı/Duran V. Aktif toplamı Kernel yoğunlukları
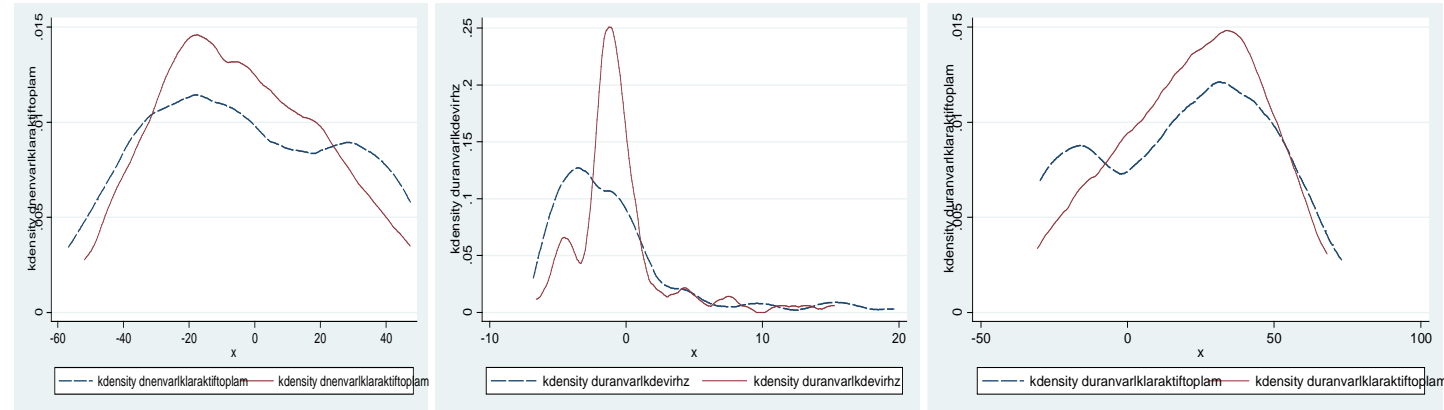

Şekil 2'de sırasıyla, dönen varlıklar aktif toplamı oranında yoğunlaşmanın halka arz öncesinde dağınık bir seyirde olduğu $(-40,40)$, sonrasında benzeri bir dağınıklıkta ancak daha yüksek seyrettiği görülmektedir. Duran varlıkların devir hızlarında yoğunluk halka arzdan önce $(-7,1)$ aralığında görülürken, halka arzdan sonrasında yoğunluğun daha az dağıldığg, yükseldiği $(-1,1)$ izlenebilmektedir. Duran varlıkların aktif toplamlarına oranı incelendiğinde, halka arzdan öncesi ve sonrasında benzer biçimde yoğunluğun olduğu $(1,50)$, halka arzdan sonra ise normal dağılıma oldukça benzer şekilde dağınıklığın ortadan kalkarak değerlerin yükseldiği belirlenmiştir. 
Şekil 3. Net İşletme Sermayesi devir hızı/Kaldıraç oranı/KV finansal borç Toplam borç Kernel yoğunlukları
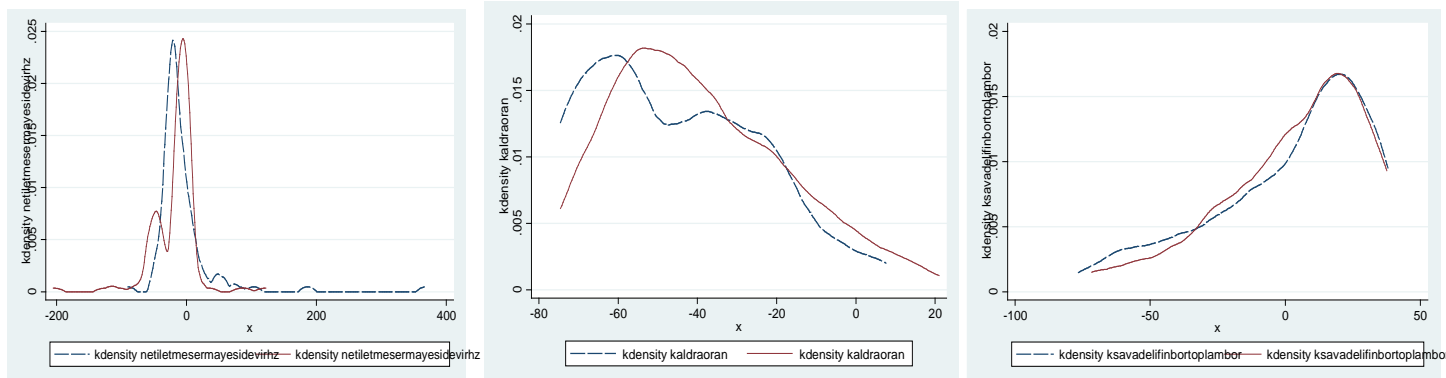

Şekil 3'de sırasıyla; Net işletme sermayesinin halka arz öncesi ve sonrası arasında önemli bir değişim göstermediği, firmaların istikrarlı oldukları görülebilmektedir. Kaldıraç oranları ise halka arz öncesinde farklı yoğunluklarda seyrettiği ancak halka arz sonrasında normal dağılıma yakın bir şekilde yoğunluklar izlenebilmektedir. Kısa vadeli finansal borçların toplam borçlara oranına bakıldığında halka arz öncesi ve sonrası arasında çok az bir farklı1ık görülebilmekte, yoğunluk değişmemektedir.

Şekil 4. KV borçlar Toplam borç/ Likidite Oranı/Maddi DV devir hızı Kernel yoğunlukları
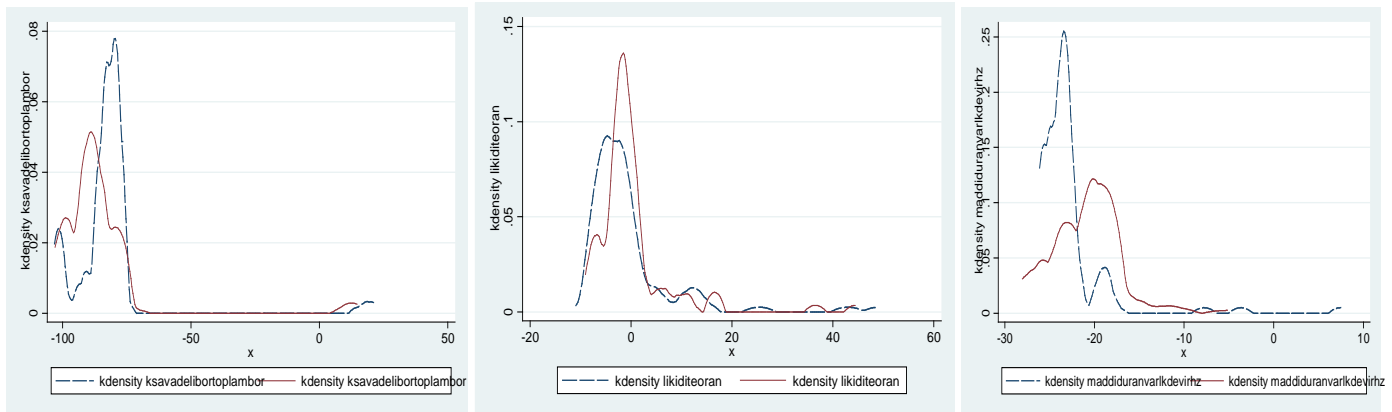

Şekil 4'de sırasıyla görülebileceği gibi, Kısa vadeli borçların toplam borçlara oranı, halka arz öncesinde, sonrasına göre benzer aralıklar içinde dağılım göstermekte ancak sonrasında azalmaktadır. Likidite oranı da aynı aralıklarda seyretmekle birlikte, halka arzdan sonra yükselmiştir. Maddi varlık devir hızları, halka arz öncesinde daha dar bir aralıkta iken, halka arzdan sonra yoğunluğun daha arttı̆̆ı ve devrin azaldığı görülebilmektedir. 
Şekil 5. Nakit oran/Net Kâr özsermaye/Net Kâr Toplam Aktifler Kernel Yoğunlukları
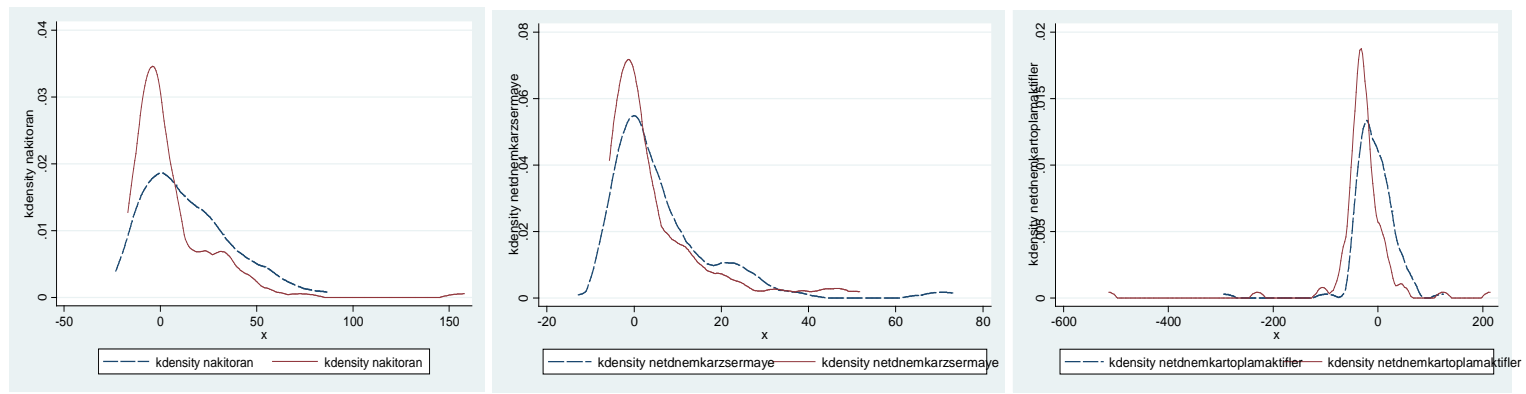

Şekil5'de sırasıyla; nakit oranın halka arzdan önce daha dağınık olduğu, ancak sonrasında yoğunluğun belli bir aralığa toparlandığı görülebilmektedir. Net kârların özsermayeye oranında halka arz öncesinde daha dağınık olan oranların, sonrasında daha yoğun olarak toparlanabildiği izlenebilmektedir. Net kârların aktif toplamlarına oranında benzer yoğunluklar görülmekte, sonrasında oranların biraz daha yükseldiği anlaşılmaktadır.

Şekil 6. VÖK Özsermaye oranı/Özsermaye devir hızı/Işsletme sermayesi devir hızı Kernel Yoğunlukları
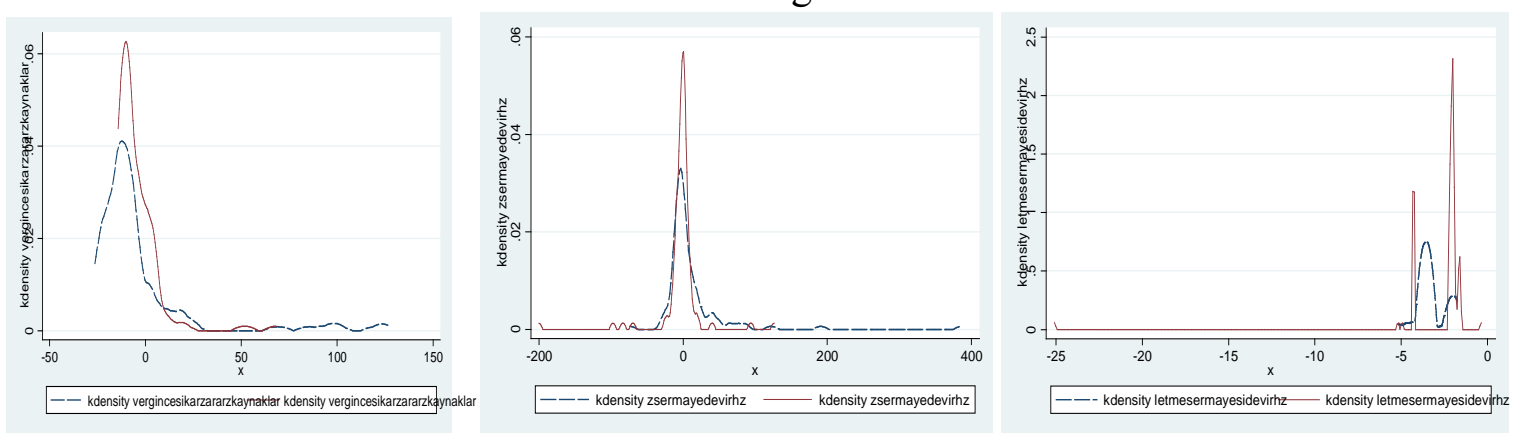

Şekil 6'da sırasıyla vergi öncesi kârların özsermayeye oranı, halka arz öncesi ve sonrasında yoğunlukları değişmiştir. Buna göre, halka arzdan önce daha benzer yoğunluklarda ancak dağınıkken halde, halka arz sonrasında da dağınık fakat artan bir yoğunluk izlenebilmektedir. İşletme sermayesi devir hızlarının halka arz öncesi ve sonrasında tamamen farklı seyirlerde, dağılımda ve yoğunlaşmada olduğu görülebilmektedir.

\section{HALKA ARZ ÖNCESİ VE SONRASINI AÇIKLAYABÍLEN FİNANSAL ORANLAR}

Halka arzdan öncesi ve sonrasında birlikte hareket eden oranları belirlemek için lojistik regresyon uygulanmıştır. Lojistik regresyon analizinin temel odağı, değişkenleri farklı gruplara ayrılarak sınıflandırılmasıdır (Çokluk, 2010: 1357; Aktaş ve Erkuş, 2009: 47). İkili (Binary) lojistik regresyon, lineer regresyonun lineerlik, normallik ve eşit varyans 
varsayımlarına göre çalışmamaktadır. Finansal oranlar, halka arz öncesi ve sonrası grupları olarak ikiye ayrılmıştır. İşlemler STATA 11 SE'de, halka açılmadan öncesi 0, sonrası 1 olarak kodlanmıştır.

Çokluk'a göre (2010: 1373), örneğin, eğer ilgilenilen değişken cinsiyet ise, herhangi bir gruba 1 (örneğin kadın) ve diğer gruba 0 (erkek) değeri atanabilir. Bu durumda katsayılar, bağımsız değişken ya da değişkenlerin, bir bireyin kadın olması olasılığı üzerindeki etkisini yansıtır. Çünkü 1 olarak kodlanan kategori "kadın"dır. Buna göre bu çalışmada halka arz öncesinde olma olasılığını açıklayan finansal yönetim politikası hakkında fikir verebilecek bağımsız değişkenler adımsal lojistik regresyon analizi yapılarak; Kısa vadeli borç/Toplam borç, İşletme sermayesi devir hızı, Cari oran, Özsermaye devir hızı, Net işletme sermayesi devir hızı ve Maddi duran varlık devir hızının açıklayıcı güçleri belirlenmiştir. Adımsal lojistik regresyonun en önemli avantajı, verilen anlamlılık düzeyine göre sinama yaparak, anlamlı olmayan değişkenleri modelden çıkartmasıdır (Rodriguez, 2007). \%99 anlamlılık düzeyine göre eldeki finansal oranlardan elde edilen sonuçlar Tablo 2'de görülmektedir. Lojistik regresyon uygulanırken, yorumlamaya imkân veren odds oranlarını hesaplayan yöntem kullanılmıştır.

Tablo 2. Lojistik regresyon sonuçları

\begin{tabular}{|c|c|c|c|c|c|}
\hline \multirow{3}{*}{ Lojistik Regresyon Sonuçları (Adımsal) } & & & \multicolumn{2}{|c|}{ Gözlem Sayısı } & 259 \\
\hline & & & \multicolumn{2}{|c|}{ Lr Ki2 (6) } & 78.44 \\
\hline & & & \multicolumn{2}{|c|}{ Olasılık $>\mathrm{Ki} 2$} & 0.0000 \\
\hline Log likelihood: -137.6512 & & & \multicolumn{2}{|c|}{ Pseudo R2 } & 0.2218 \\
\hline İkili grup & $\operatorname{Exp} \widehat{\beta_{1}}$ & Std.Hata & $\mathrm{z}$ & {$[\% 95$} & en Aralığı] \\
\hline Aktif Devir Hızı & 1.910135 & 0.336892 & 3.67 & 1.351876 & 2.698928 \\
\hline Maddi Duran Varlık Devir Hızı & 1.217297 & 0.048262 & 4.96 & 1.126287 & 1.315662 \\
\hline Net işletme sermayesi devir hızı & 0.980677 & 0.006309 & -3.03 & 0.968389 & 0.993121 \\
\hline Dönen Varlıklar /Toplam Aktifler & 1.272128 & 0.060795 & 5.04 & 1.158382 & 1.397044 \\
\hline Duran Varlıklar/ Toplam Aktifler & 1.302605 & 0.627008 & 5.49 & 1.185332 & 1.43148 \\
\hline
\end{tabular}

Yukarıdaki sonuçlara göre, en önemli değişkenin aktif devir hızı olduğu tespit edilmiştir $\left(\operatorname{Exp} \widehat{\beta_{2}}=1.910\right)$, aktif devir hızındaki 1 birim artışın, halka arz olasılığını 1.910 kat arttırdığı söylenebilir. Maddi duran varlık devir hızındaki 1 birimlik artışın, halka arz olasılığını 1.21 kat artırdığı, Net işletme sermayesi devir hızındaki 1 birimlik artışın, halka arz olasılığını 0.98 kat artırdığı, dönen varlıklar/toplam aktifler oranındaki 1 birimlik artışın, halka arz olasılığını 1.272 kat artırdığı, duran varlıklar/toplam aktifler oranındaki 1 birimlik artışın, halka arz olasılığını 1.3 kat artırdığı şeklinde yorumlanabilmektedir.

\section{SONUÇ}

Elde edilen sonuçlar, halka arzdan sonra firmaların finansal yönetim politikalarını göstermesi bakımından önemli olduğu gibi, firmaların halka arz öncesindeki halka arzdan elde ettiklerini nasıl kullandığını göstermesi bakımından da önemlidir. Halka arz öncesi ve sonrası için finansal oranlar karşılaştırıldığında incelenen hemen bütün oranların öncesine göre farklı olduğu belirlenmiştir. Öncesi ve sonrası olarak belirlenmiş iki grup arasında 
değişim olasılıkları oldukça yüksektir. Bu durum firmaların finansal hayatında halka arzın yarattığı etkilerden bir tanesinin de finansal politikalardaki değişimler olduğunu göstermektedir.

Firmalar halka arza hazırlık süreçleri içindeyken, halka arz sonrasına göre en fazla değişim gösteren oranların (Aktif devir hızı, Maddi duran varlık devir hızı, net işletme sermayesi devir hızı, dönen varlıklar/toplam aktifler ve duran varlıklar/toplam aktifler olduğu belirlenmiştir. Halka arz sonrasında elde edilen fonlarla beklenebileceği gibi aktifler büyüyecektir ancak, aktif devir hızındaki artışla ilgili olarak satışların aktif artışına göre daha fazla artmış olduğu söylenebilir. Halka arzın güdülerinden biri olan bilinirliğin arttırılması ve güvenli firma imajının buna hizmet etmiş olduğu düşünülebilir. Bu bulgu, Demers ve Levennen'in (2003:430), bulgularını destekler niteliktedir. Ayrıca, halka arz öncesi var olan yoğunlaşma, birbirine yakın oranlarda toplanma, halka arz sonrasına göre daha fazladır. Halka arz sonrasında, firmaların aktif devir hızlarındaki benzerlikler azalmıştır.

Maddi duran varlıklar/toplam aktifler ve duran varlıklar/toplam aktiflerin açıklayıcı rolü, firmanın halka arzdan sonra sabit yatırımlar yapmış olmasından ileri gelmektedir. $\mathrm{Bu}$ yönüyle de halka arzın bir diğer güdüsü olan firma büyümesinin, halka arz öncesine göre anlamlı bir şekilde gerçekleştiği söylenebilir. Bulgu Mikkelson, Partch ve Shah'ın (1997) ve Schiozer, Oliveira ve Saito'nun (2010) bulgularını destekler niteliktedir. Benzer biçimde dönen varlıklar/toplam aktiflerin azalması da bu savı desteklemektedir. Maddi duran varlıkların devir hızı, halka arz öncesinde firmalarda daha dağınık bir halde iken devrin düşerek yoğunlaşmanın artmış olması da firma büyümesi tezini doğrular niteliktedir.

Net işletme sermayesinin ise, halka arzdan öncesine göre anlamlı bir şekilde azalması, artan satışlara bağlı olarak artmış olan stok veya alacakların devir hızlarındaki düşüşler olmasına bağlanabileceği gibi arttığı görülen kısa vadeli yabancı kaynaklar da bu düşüşü açıklayabilir. Kısa vadeli yabancı kaynaklardaki artışların açıklayıcılığının daha fazla olması gerekir çünkü dönen varlık finansmanına aktarılan fonların duran varlıklardan çok daha az olduğu görülmektedir. Firma kârlılıklarını gösterir oranlardaki azalış, halka arz öncesindeki kârlarla ilgili bir şüphe yaratmakta, makyajlama olgusunu hatırlatmaktadır. Halka arzdan önce ve sonrasında net işletme sermayesi oranlarındaki yoğunluğun pek değişim göstermediği, borçlanma, alacak, stok ve nakitle ilgili uygulamaların çok değişmediği düşünülebilir.

Firmaların halka arz olasılıkları logaritmik regresyonun bir sonucu olarak ortaya çıkmıştır. Halka arz öncesinde firmaların ilgili oranlarının izlenmesiyle finansman davranışlarının belirlenmesi, halka arz sonrasında da değerlidir çünkü firmaların halka arz yoluyla elde ettikleri finansmana ilişkin davranışlarının ve varsa meydana gelen etkilerin izlenmesi yatırımcılar ve kreditörler açısından, halka arzdaki gerçek güdülerin ortaya çıkması bakımından önemlidir. Sonraki çalışmalarda daha geniş ve elverişli bir örneklem kütlesine, grupların ayrıştırılmasını sağlayan diğer analizler (diskriminant ve faktör analizleri) ile halka arz öncesi ve sonrasına dair finansal karakteristikler daha iyi belirlenebilecektir. Aynı kümelerde yer alan firmaların muhasebe şirketlerinin belirlenmesi ile de benzeri muhasebe uygulamalarına sahip oluşun bir etkisi olup olmadığı da araştırılabilir. 


\section{KAYNAKLAR}

Aktaş, Cengiz - Erkuş, Orkun (2009), "Lojistik Regresyon Analizi ile Eskişehir'in Sis Kestiriminin İncelenmesi”, İstanbul Ticaret Üniversitesi Fen Bilimleri Dergisi, 8,16, ss. 47-61

Alt1, Aydoğan (2005), “IPO Market Timing”, Review of Financial Studies, 18, 2, pp. 1105 1138

Aperg1s, Emmanuel - Aperg1s, Nicholas (2016), “The 11/13 Paris terrorist attacks and stock prices: The case of the international defense industry”, Finance Research Letters, 17, pp. 186-192

Brau, James. C. - Francis, Bill - Kohers, Ninon (2003), “The choice of IPO versus takeover: Empirical evidence”, The Journal of Business, 76, 4, pp. 583-612

Brau, James C. (2010), "Why do firms go public?”, Oxford Handbook of Entrepreneurial Finance. https://ssrn.com/abstract=1649008, ( 08.11.2017)

Basile, I.; (1988), “M. Cattaneo et al. eds.: L'ammissione Alla Quotazione di Borsa: Un'analisi Interdisciplinare.” Gil Intermediary Creditizi e la Quotazione di Borsa. İçinde PAGANO, Marco - PANETTA, Fabio - ZINGALES, Luigi (1998), "Why Do Companies Go Public? An Empirical Analysis”, Journal of Finance, 53, pp. 27-64

Brealy, Richard - Leland Hayne E. - Pyle, David H. (1977), "Information asymmetries, financial structure and financial intermediation”, Journal of Finance, 32, May, pp. 371-87.

Chemmanur, Thomas J. - Fulghierı, Paolo (1999), “A theory of the going-public decision”, Review of Financial Studies, 12, 2, pp. 249-279

Çokluk, Ömay (2010), “Lojistik regresyon analizi: Kavram ve Uygulama. Kuram ve Eğitim Bilimleri”, 10, 3, ss. 1357-1407

Demers, Elizabeth - Lewellen, Katharina (2003), “The marketing role of IPOs: evidence from internet stocks”, Journal of Financial Economics, 68, 3, pp. 413-437

Kım, Woojin - Weisbach, Michael (2005), “Do firms go public to raise capital?” (No. w11197). National Bureau of Economic Research, http://www.nber.org/papers/w11197, ( 08.11.2017 )

Kraus, Alan - Litzenberger, Robert H. (1973), “A state-preference model of optimal financial leverage”, The Journal of finance, 28, 4, pp. 911-922

Lemmon, Michael L. - Roberts, Michael R. - Zender, Jaime F. (2008), "Back to the beginning: persistence and the cross-section of corporate capital structure", The Journal of Finance, 63, 4, pp. 1575-1608 
Mikkelson, Wayne H. - Partch, M. Megan - Shah, Ksitij (1997), “Ownership and operating performance of companies that go public”, Journal of financial economics, 44, 3, pp. 281-307

Pagano, Marco - Panetta, Fabio - Zingales, Luigi (1996), "The stock market as a source of capital: Some lessons from initial public offerings in Italy”, European Economic Review, 40, 3, pp. 1057-1069

Pagano, Marco - Panetta, Fabio - Zıngales, Luigi (1998), "Why Do Companies Go Public? An Empirical Analysis”, Journal of Finance, 53, pp. 27-64

Rajan, Raghuram - Servaes, Henri (1997), “Analyst following of initial public offerings”, Journal of Finance, 52, June, pp. 507-29

Rodríguez, German (2007), “Lecture Notes on Generalized Linear models” http://data.princeton.edu/wws509/notes/ , ( 05.05.2017)

Schızer, Rafael F. - Olıveıra, Raquel F. - Saito, Richard (2010), "Why do Banks go Public? Evidence from the 2005-2007 wave of Brazilian Bank IPOs,”, Central Bank of Brazil working paper, https://papers.ssrn.com/sol3/papers.cfm?abstract_id=1470994, (08.11.2017)

Schultz, Paul (2003), "Pseudo Market Timing and the Long-Run Underperformance of IPOs”, Journal of Finance, 58, pp. 483-517

Welch, Ivo (2004), “Capital Structure and Stock Returns”, Journal of Political Economy, 112, 1, pp. 106-131. 
